\title{
Ultimate strength of simply supported plate with opening under uniaxial compression
}

\author{
Chang-Li $\mathrm{Yu}^{1,2}$ and Joo-Sung Lee ${ }^{1}$ \\ ${ }^{1}$ School of Naval Architecture \& Ocean Engineering, University of Ulsan, Ulsan, Korea \\ ${ }^{2}$ School of Naval Architecture, Harbin Institute of Technology, Weihai, China
}

\begin{abstract}
Unstiffened plates are integral part of all kinds of structures such as ship and offshore oil platforms. Openings are unavoidable and absolutely reduce the ultimate strength of structures. In this study, the finite element analysis package, ABAQUS, is used to analyze the behavior of unstiffened plate with rectangular opening. The rectangular opening form is divided into two cases. In casel, opening depth is constant, but opening width is varied. Meanwhile, in case 2 opening width is fixed and opening depth is varied. Besides, for the two different form opening, the effect of plate slenderness parameter $(\beta)$, opening area ratio $(A R)$ and opening position ratio $(P R)$ on the ultimate strength of plate with opening under axial compression are presented. It has been found that the ultimate strength of plate ofcaselis much more sensitive to the plate slenderness parameter $(\beta)$ and opening area ratio (AR) than that of case2. However, for case1, opening position (PR) almost has no effect on the ultimate strength, whereas, regardingcase2, the influence of opening position (PR) depends on the plate slenderness parameter $(\beta)$. Based on nonlinear regression analysis, three design formulae are not only developed butalso approved reasonably for the practical engineering design.
\end{abstract}

KEY WORDS: Ultimate strength; Rectangular opening; Simply supported plate; Uniaxial compression; Design equation; Formulae fitting.

NOMENCLATURE

$\begin{array}{llll}A & \text { Length of plate } & \sigma_{u} & \text { Ultimate stress of plate } \\ B & \text { Width of plate } & \beta & \text { Plate slenderness parameter } \\ t & \text { Thickness of plate } & v & \text { Poisson ratio } \\ a & \text { Depth of opening } & E & \text { Modulus of elasticity } \\ b & \text { Width of opening } & x & \text { Distance from center of opening to center of plate } \\ A_{c} & \text { Area of opening } & A R & \text { Opening area ratio (Ratio of area of opening to area of plate) } \\ A_{p} & \text { Area of plate } & P R & \text { Opening position ratio (ratio of } x \text { to } \frac{A}{2} \text { or } \frac{B}{2} \text { ) }\end{array}$

\section{INTRODUCTION}

Stiffened and unstiffened steel flat panels form the basic members for the deck structure and habitation units in ship as well as offshore structures. Even though for stiffened panels, thin plates between stiffeners are integral part of flat panels. The ultimate strength of these elements is important from view point of design and safety since collapse of plate due to local buckling is

Corresponding author: Joo-Sung Lee

e-mail:jslee2@ulsan.ac.kr 
one of the important basic failure modes. A typical ship deck between the bulkheads and deep longitudinal components is shown in Fig. 1.The bending rigidities of the boundary edges of plates between transverse frames and longitudinal stiffeners are quite high compared with that of the plate itself. The rotational restraints along the plate edges can be assumed to be small for plates subjected to axial compression. Hence, the plate elements in the current study are considered as simply supported along all edges.



Fig. 1 A typical ship deck in between the bulkhead.

In general, the loading cases in ship and offshore panels are complex, which include axial, biaxial compression and the combination of in-plane loading with lateral pressure. Among all loading cases, uniaxial loading is the basic and the most common case for unstiffened plate structure. Additionally, yielding strength is considered as the ultimate strength of plate as it is subjected to uniaxial tension. It is, therefore, assumed that all these unstiffened plates are designed to withstand only the uniaxial compression due to sagging and hogging moments.

Openings are required for passage of piping, ducts and other accessories for maintenance purposes. In practice, the openings are generally located in the plate such that, center of opening coincides with the center of plate or along longitudinal direction. However, there are some exceptions to above rules. Thus the case of position of openings changed along transverse direction may also be found in practice. Rectangular opening and circular opening are common opening types, in this study, only rectangular opening is considered. Even though the common manhole's size is $800 \times 600 \mathrm{~mm}$, they are not same in ship and offshore structure. Openings are often stiffened by flanges or double plate. However, in this paper, we focus more on the influences of different design parameters with respect to plate and opening on the ultimate strength of structure, which is important during the initial design stage. Therefore, we simplified the opening without flange or double plate.

\section{Review of existing fruit and merits over them}

It is evident that opening reduces the ultimate strength of plate, and a lot of literatures on the ultimate strength of plate with different openings and subjected to various load are described. In the literature, Narayanan and Chow (1984) developed design charts based on ultimate capacity of uniaxial compressed perforated plates with square and circular opening. Roberts and Azizian (1984) generated interaction curves for ultimate strength of square plates with central square and circular holes subjected to uniaxial compression, biaxial compression and pure shear. Narayanan and Chan (1985) presented design charts based on ultimate strength of plates containing circular holes under linearly varying edge displacements. Jwalamalini et al. (1992) developed the design charts for the stability of simply supported square plate with opening under in-plane loading as uniform compression and trapezoidal loads. Madasamy and Kalyanaraman (1994) presented the analysis of plated structures with rectangular cutouts and internal supports using the spline finite strip method. Motok (1997) carried out stress concentration studies on the contour of a plate opening of an arbitrary corner radius of curvature. Shanmugam et al. (1999) presented the design formula for simply supported and clamped boundary conditions. Paik et al. (2001) presented ultimate strength formulations for ship plating under combined biaxial compressions/tension, edge shear, and lateral pressure loads. Bambach and Rasmussen (2002) carried out the test of unstiffened elements under different combined compression and bending cases. Khaledet et al. (2004) employed finite element method to determine the elasto-plastic buckling stress of uniaxial loaded simply 
supported square and rectangular plates with circular openings. Kumar et al. (2007) used the commercial package ANSYS to analyze ultimate strength of square plate with central rectangular opening along the loading direction under axial compression. Mohtaram et al. (2011) studied the experimental and numerical investigation of buckling in rectangular steel plates with grooveshape cut out and clamped supported at upper and lower ends and free supported in the other ends.

Based on above practical engineering analysis and literature review, it is observed that there is lack of studies on the ultimate strength of square plate with varying position openings under axial compression. In the condition of having no impact on design function, it is very significant to know where to cut the openings so that the ultimate strength is reduced as least as possible. Additionally, Cui and Mansour (1998) illustrated that "because of the complexity of the problem, the most frequent answer to the method for determining the ultimate strength of plates accurately is the use of finite element method (FEM)". However, FEM is time consuming and this is not favored by designers. Therefore, convincing design formulae for ultimate strength of plate with opening are still in urgent need for the designer.

There are several merits over the research works mentioned before. First of all, as a special case, longitudinal opening (as defined below) is taken into account, secondly, the influence of opening location to the ultimate strength is presented. The design formulae proposed here have enough precision for engineering application and can be employed in practice.

\section{NONLINEAR FINITE ELEMENT STUDY}

Generally speaking, longitudinally framed system is used frequently in ship and offshore structure. The longitudinally framed system has remarkably lower spacing between longitudinal stiffeners as compared to the spacing between web frames. Toulios and Caridis (2002) proposed that ultimate strength of unstiffened plate without opening to be maximum for an aspect ratio of $A / B=1.0$, and also presented the reduced factors induced by aspect ratio ranged from 1 to 3.5 . In practical application, the corresponding reduced factor of aspect ratio should be taken into consideration and compensation should be made to the ultimate strength of the structure. Therefore, an unstiffened plate of size $500 \times 500 \mathrm{~mm}(A \times B)$ is taken into account for the present study. Plate slenderness parameter is defined as $\beta=\frac{B}{t} \sqrt{\frac{\sigma_{y}}{E}}$, of which practical range covers from1.0 to 4.5 in ship structures. With keeping width of plate(B) constant as $500 \mathrm{~mm}$, and varying thickness of plate(t) as 5, 6, 8, 10, 12 and $15 \mathrm{~mm}$, respectively, nonlinear finite element analysis has been carried out. Rectangular opening is provided into two main cases as shown in the Fig. 2. The case1 can be called transverse opening, of which depth (a) is kept constant as $100 \mathrm{~mm}$, and the width (b) is varied as 50, 100, 150, 200, 250, 300, 350, 400 and $450 \mathrm{~mm}$, which are denotedasP1, P2, P3, P4, P5, P6, P7, P8 and P9 hereafter. Meanwhile,case 2 can be called longitudinal opening, of which width (b) is kept constant as $100 \mathrm{~mm}$ and the depth (a) is varied as 50, 100, 150, 200, 250, 300, 350, 400 and $450 \mathrm{~mm}$, which are denoted as L1, L2, L3, L4, L5, L6, L7, L8 and L9 hereafter. Area ratio $(A R)$ of rectangular opening is defined as the ratio of opening area $\left(A_{c}\right)$ to area of plate $\left(A_{p}\right)$. For the present study, the area ratio $(A R)$ is varied as $0.02,0.04,0.06,0.08,0.10,0.12,0.14,0.16$ and 0.18 . Position ratio ( $P R$ ) of rectangular opening is defined as twice the ratio of distance between plate center and opening center $(x)$ to the edge length of plate ( $A$ or $B$ ) as shown in the Fig. 3. Here, the half-length of plate edge is $250 \mathrm{~mm}$, thus the position ratio is varied as 0.0 ,

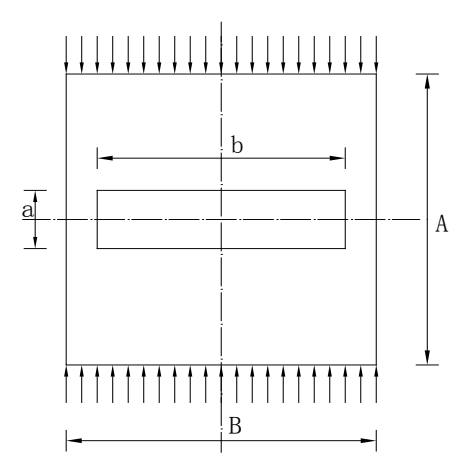

(case1)



(case2)

Fig. 2 Unstiffened plates with center rectangular opening. 
$0.2,0.4,0.6$ and 0.8 . The yield strength $\left(\sigma_{y}\right)$, modulus of elasticity $(E)$ and Poisson ratio $(v)$ of plate are $250 M P a$, $2 \times 10^{5} \mathrm{MPa}$ and 0.3 , respectively. As explained in the previous section, all sides of the plate are assumed to be simply supported. The unloaded sides are allowed to deform in-plane but remain straight. This is achieved by coupling the deformation of nodes in that direction. This condition can reflect the actual situation of unstiffened plate between longitudinal and transverse stiffeners.



Fig 3 Definition of position ratio ( $P R)$.

The finite element analysis package, ABAQUS, is used for modeling, analysis and post processing of unstiffened plate with rectangular opening under uniaxial compression. Modeling of unstiffened plate involves generation of two square plates of size $500 \times 500 \mathrm{~mm}$ and $a \times b$ (opening depth $\times$ opening width) respectively. Using the "cut geometry" option available in the "Merge/Cut Instances" operation under the "Assembly" part, the rectangular area is deleted. Thus the geometry of an unstiffened plate with rectangular opening is developed. Fig. 4 shows a typical finite element mesh used in the present analysis, the unstiffened plate is discretized into 8 node quadrilateral elements. The element has six degrees of freedom per each node: three translations $\left(u_{x}, u_{y}\right.$, and $\left.u_{z}\right)$ and three rotations $\left(R_{x}, R_{y}\right.$, and $\left.R_{z}\right)$. Boundary condition is shown in Fig. 5. All the nodes along the boundary are restrained for deflection and rotation in vertical direction $\left(u_{z}\right.$ and $\left.R_{z}=0\right)$. Additionally, all the nodes along unloaded (longitudinal) edges are coupled for in-plane displacement $\left(u_{x}\right)$ to make sure that the displacement along the plate end is uniform. All the nodes along loaded edge are MPC constrained in one reference point, in which the displacement loading is applied.



Fig. 4 Typical finite element mesh.



Fig. 5 Boundary conditions.

The plating in ships is usually continuously welded along the plate-stiffener intersection and it is well established that the welding process introduces a residual stress field and an associated initial distortion in the plate and stiffener. The initial geometrical imperfections and residual stresses significantly influence the ultimate strength of stiffened panels. However, regarding 
the object of study to be pure unstiffened plate, then it can be safely assumed that no welding or other manufacturing process was implemented. Hence no measurement was made to determine the initial distortion and residual stresses of plate. In the future study, the ultimate strength of stiffened panels with opening will be carried out, and novel method to consider the initial distortion and residual stresses will be proposed. Even for pure plating with opening, if initial imperfections are taken into account, the work of various authors on the effect of initial imperfections on the ultimate strength of plate without opening, such as Paik et al. (1999) and Cui and Mansour (1998) and so on, can be referred. Both geometric and material nonlinearities are considered in the analysis. Large displacement option is activated in geometric nonlinear analysis. Material nonlinearity is modeled using an incremental plasticity theory assuming the material to be elastic-ideal plastic. The nonlinear calculation type is "Static, Riks", maximum number of increments is 100 , initial and minimum values of "Arc length increment" are 0.1 and $1 \times 10^{-12}$, respectively. The mesh size is selected as $25 \times 25 \mathrm{~mm}$ to balance the calculation convergence and consuming time, more details can be found in Table 1 (Kumar et al., 2007), that were obtained by a study of unstiffened plate without opening.

Table 1 Convergence study.

\begin{tabular}{|c|c|c|c|c|}
\hline No. & Mesh & No. of Elements & Ultimate Load $(K N)$ & CPU Time $($ sec $)$ \\
\hline 1 & Coarse & 25 & 400.11 & 5.86 \\
2 & Medium & 100 & 393.66 & 8.19 \\
3 & Fine & 400 & 392.93 & 68.22 \\
4 & Very Fine & 1600 & 392.26 & 1478.98 \\
\hline
\end{tabular}

The size of tested plate is $500 \times 500 \mathrm{~mm}$, and thickness is $3.2 \mathrm{~mm}$. The yield strength of plate $\left(\sigma_{y}\right)$ is assumed as $250 \mathrm{MPa}$ with modulus of elasticity $(E)$ as $2.058 \times 10^{5} \mathrm{MPa}$ and Poisson ratio $(v)$ of 0.3 . Comparison of load-deflection among the published results of Paik et al. (2001), Kumar et al. (2007) and the present study is made to confirm that the present nonlinear analysis procedure is reasonable.



Fig. 6 Comparison between analytical solution, and approximate solutions by ANSYS and ABAQUS.

\section{RESULTS AND DISCUSSION}

A typical plot for the models with thickness of $8 \mathrm{~mm}(\beta=2.21)$ is shown in Fig. 7, and ultimate load-carrying capacity is defined as the peak point. The results for other models with transverse center opening are shown in Table 2 including the 
comparison with published result (Kumar et al., 2007). We can found the discrepancy rate between published results and present results is relatively.



Fig. 7 Typical plot of Axial load/axial deformation for model P4 when $\beta=2.27$.

Fig. 8 illustrates the effect of plate slenderness parameter on ultimate strength of models with transverse center opening for varied opening area ratio. It is observed that, for slenderness parameter of 1.18 3.54 and area ratio of more than 0.12 , the models with transverse center rectangular opening fail by yielding. Otherwise, as plate slenderness parameter is less than 1.47 , they still fail by yielding regardless of opening area ratio. Models with longitudinal opening do not fail by yielding, and their ultimate strength change a little for different opening area ratio.

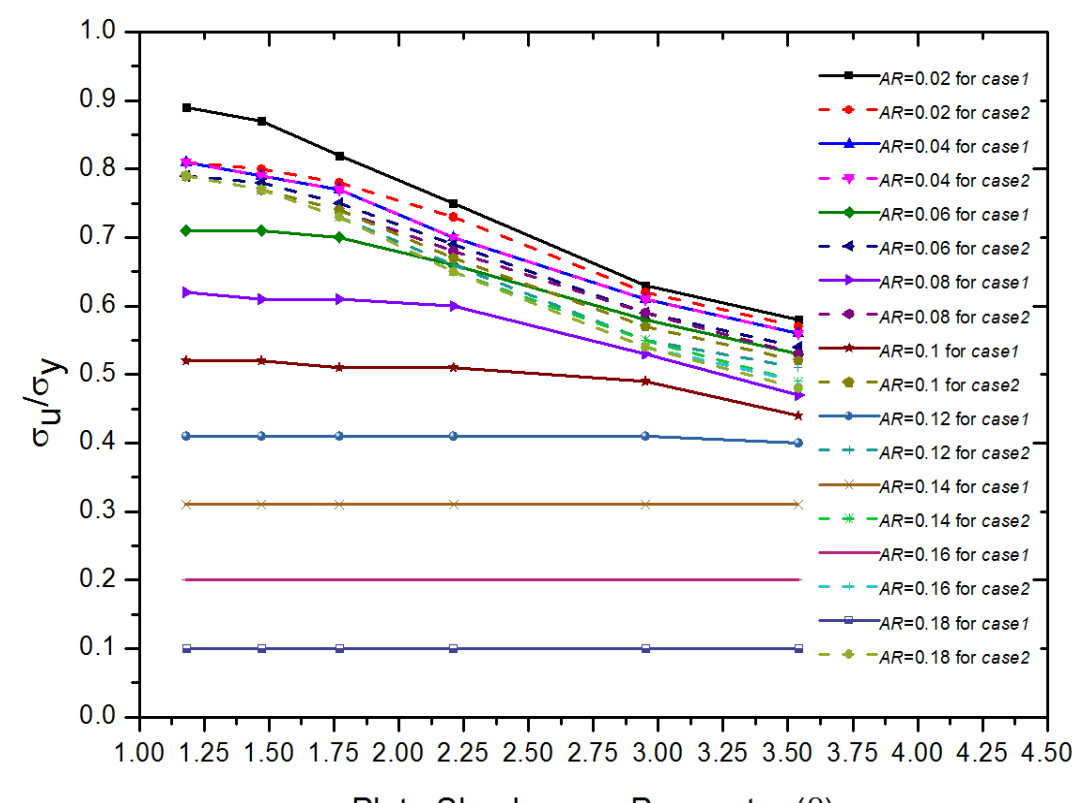

Plate Slenderness Parameter $(\beta)$

Fig. 8 Effect of plate slenderness parameter $(\beta)$ on ultimate strength of models with transverse opening for varied opening area ratio $(A R)$. 
Table 2 Results for models with transverse center opening.

\begin{tabular}{|c|c|c|c|c|c|c|c|c|c|c|c|c|c|}
\hline Model & $\beta$ & $A R$ & $\begin{array}{c}\text { Ultimate } \\
\operatorname{load}\left(P_{u}\right) \\
K N\end{array}$ & $\frac{\sigma_{u}}{\sigma_{y}}$ & $\begin{array}{c}\frac{\sigma_{u}}{\sigma_{y}} \\
\text { (Kumar) }\end{array}$ & $\begin{array}{c}\text { Discre- } \\
\text { pancy } \\
\text { rate }\end{array}$ & Model & $\beta$ & $A R$ & $\begin{array}{c}\text { Ultimate } \\
\operatorname{load}\left(P_{u}\right) \\
K N\end{array}$ & $\frac{\sigma_{u}}{\sigma_{y}}$ & $\begin{array}{c}\frac{\sigma_{u}}{\sigma_{y}} \\
\text { (Kumar) }\end{array}$ & $\begin{array}{c}\text { Discre- } \\
\text { pancy } \\
\text { rate }\end{array}$ \\
\hline \multirow{6}{*}{$\mathrm{P} 1$} & 3.54 & \multirow{6}{*}{0.02} & 362.65 & 0.58 & 0.57 & $1.69 \%$ & \multirow{6}{*}{ P6 } & 3.54 & \multirow{6}{*}{0.12} & 249 & 0.40 & 0.40 & $0.71 \%$ \\
\hline & 2.95 & & 472.683 & 0.63 & 0.61 & $2.86 \%$ & & 2.95 & & 306.052 & 0.41 & 0.42 & $-3.71 \%$ \\
\hline & 2.21 & & 747.801 & 0.75 & 0.72 & $3.96 \%$ & & 2.21 & & 413.28 & 0.41 & 0.42 & $-2.13 \%$ \\
\hline & 1.77 & & 1030 & 0.82 & 0.89 & $-7.83 \%$ & & 1.77 & & 518.529 & 0.41 & 0.43 & $-2.77 \%$ \\
\hline & 1.47 & & 1300 & 0.87 & 0.92 & $-5.37 \%$ & & 1.47 & & 622.1 & 0.41 & 0.43 & $-2.80 \%$ \\
\hline & 1.18 & & 1670 & 0.89 & 0.92 & $-2.75 \%$ & & 1.18 & & 776.734 & 0.41 & 0.43 & $-2.92 \%$ \\
\hline \multirow{6}{*}{ P2 } & 3.54 & \multirow{6}{*}{0.04} & 347.876 & 0.56 & 0.55 & $1.62 \%$ & \multirow{6}{*}{ P7 } & 3.54 & \multirow{6}{*}{0.14} & 192.902 & 0.31 & 0.33 & $-6.75 \%$ \\
\hline & 2.95 & & 460.555 & 0.61 & 0.59 & $4.29 \%$ & & 2.95 & & 231.561 & 0.31 & 0.36 & $-15.17 \%$ \\
\hline & 2.21 & & 703.908 & 0.70 & 0.68 & $2.82 \%$ & & 2.21 & & 308.258 & 0.31 & 0.31 & $-0.63 \%$ \\
\hline & 1.77 & & 956.9 & 0.77 & 0.82 & $-6.98 \%$ & & 1.77 & & 385.041 & 0.31 & 0.31 & $-0.71 \%$ \\
\hline & 1.47 & & 1190 & 0.79 & 0.83 & $-3.95 \%$ & & 1.47 & & 461.61 & 0.31 & 0.31 & $-0.81 \%$ \\
\hline & 1.18 & & 1520 & 0.81 & 0.83 & $-1.86 \%$ & & 1.18 & & 576.634 & 0.31 & 0.31 & $-0.89 \%$ \\
\hline \multirow{6}{*}{ P3 } & 3.54 & \multirow{6}{*}{0.06} & 330.245 & 0.53 & 0.52 & $1.42 \%$ & \multirow{6}{*}{ P8 } & 3.54 & \multirow{6}{*}{0.16} & 126.568 & 0.20 & 0.25 & $-17.37 \%$ \\
\hline & 2.95 & & 436.998 & 0.58 & 0.56 & $4.21 \%$ & & 2.95 & & 151.741 & 0.20 & 0.25 & $-17.45 \%$ \\
\hline & 2.21 & & 662.888 & 0.66 & 0.65 & $1.55 \%$ & & 2.21 & & 202.128 & 0.20 & 0.20 & $1.59 \%$ \\
\hline & 1.77 & & 872.301 & 0.70 & 0.75 & $-6.75 \%$ & & 1.77 & & 252.41 & 0.20 & 0.20 & $1.49 \%$ \\
\hline & 1.47 & & 1060 & 0.71 & 0.74 & $-3.99 \%$ & & 1.47 & & 302.722 & 0.20 & 0.20 & $1.43 \%$ \\
\hline & 1.18 & & 1340 & 0.71 & 0.74 & $-2.90 \%$ & & 1.18 & & 378.134 & 0.20 & 0.20 & $1.34 \%$ \\
\hline \multirow{6}{*}{ P4 } & 3.54 & \multirow{6}{*}{0.08} & 295.893 & 0.47 & 0.49 & $-2.49 \%$ & \multirow{6}{*}{ P9 } & 3.54 & \multirow{6}{*}{0.18} & 62.62 & 0.10 & 0.12 & $-17.37 \%$ \\
\hline & 2.95 & & 396.321 & 0.53 & 0.52 & $1.27 \%$ & & 2.95 & & 75.09 & 0.10 & 0.12 & $-17.42 \%$ \\
\hline & 2.21 & & 597.49 & 0.60 & 0.62 & $-3.99 \%$ & & 2.21 & & 100.008 & 0.10 & 0.10 & $1.45 \%$ \\
\hline & 1.77 & & 761.184 & 0.61 & 0.67 & $-8.65 \%$ & & 1.77 & & 124.901 & 0.10 & 0.10 & $1.36 \%$ \\
\hline & 1.47 & & 921.553 & 0.61 & 0.64 & $-4.42 \%$ & & 1.47 & & 149.97 & 0.10 & 0.10 & $1.42 \%$ \\
\hline & 1.18 & & 1160 & 0.62 & 0.64 & $-3.76 \%$ & & 1.18 & & 187.107 & 0.10 & 0.10 & $1.22 \%$ \\
\hline \multirow{6}{*}{ P5 } & 3.54 & \multirow{6}{*}{0.1} & 275.752 & 0.44 & 0.44 & $-0.47 \%$ & & & & & & & \\
\hline & 2.95 & & 367.92 & 0.49 & 0.48 & $2.17 \%$ & & & & & & & \\
\hline & 2.21 & & 508.551 & 0.51 & 0.55 & $-7.51 \%$ & & & & & & & \\
\hline & 1.77 & & 642.687 & 0.51 & 0.54 & $-4.69 \%$ & & & & & & & \\
\hline & 1.47 & & 776.127 & 0.52 & 0.54 & $-4.09 \%$ & & & & & & & \\
\hline & 1.18 & & 972.588 & 0.52 & 0.54 & $-3.86 \%$ & & & & & & & \\
\hline
\end{tabular}


Table 3 Results for models with longitudinal center opening.

\begin{tabular}{|c|c|c|c|c|c|c|c|c|c|c|c|c|c|c|}
\hline Model & $\beta$ & $A R$ & $\begin{array}{c}\text { Ultimate } \\
\text { Load }\left(P_{u}\right) \\
\qquad K N\end{array}$ & $\frac{\sigma_{u}}{\sigma_{y}}$ & Model & $\beta$ & $A R$ & $\begin{array}{c}\text { Ultimate } \\
\operatorname{Load}\left(P_{u}\right) \\
K N\end{array}$ & $\frac{\sigma_{u}}{\sigma_{y}}$ & Model & $\beta$ & $A R$ & $\begin{array}{c}\text { Ultimate } \\
\operatorname{Load}\left(P_{u}\right) \\
K N\end{array}$ & $\frac{\sigma_{u}}{\sigma_{y}}$ \\
\hline \multirow{6}{*}{ L1 } & 3.54 & \multirow{6}{*}{0.02} & 353.432 & 0.57 & \multirow{6}{*}{ L4 } & 3.54 & \multirow{6}{*}{0.08} & 330.357 & 0.53 & \multirow{6}{*}{ L7 } & 3.54 & \multirow{6}{*}{0.04} & 308.347 & 0.49 \\
\hline & 2.95 & & 468.302 & 0.62 & & 2.95 & & 438.818 & 0.59 & & 2.95 & & 412.96 & 0.55 \\
\hline & 2.21 & & 725.429 & 0.73 & & 2.21 & & 679.526 & 0.68 & & 2.21 & & 653.25 & 0.65 \\
\hline & 1.77 & & 976.822 & 0.78 & & 1.77 & & 927.545 & 0.74 & & 1.77 & & 917.275 & 0.73 \\
\hline & 1.47 & & 1200 & 0.80 & & 1.47 & & 1160 & 0.77 & & 1.47 & & 1150 & 0.77 \\
\hline & 1.18 & & 1520 & 0.81 & & 1.18 & & 1490 & 0.79 & & 1.18 & & 1490 & 0.79 \\
\hline \multirow{6}{*}{ L2 } & 3.54 & \multirow{6}{*}{0.04} & 347.867 & 0.56 & \multirow{6}{*}{ L5 } & 3.54 & \multirow{6}{*}{0.1} & 322.023 & 0.52 & \multirow{6}{*}{ L8 } & 3.54 & \multirow{6}{*}{0.06} & 305.918 & 0.49 \\
\hline & 2.95 & & 460.555 & 0.61 & & 2.95 & & 427.533 & 0.57 & & 2.95 & & 406.245 & 0.54 \\
\hline & 2.21 & & 703.908 & 0.70 & & 2.21 & & 667.535 & 0.67 & & 2.21 & & 649.567 & 0.65 \\
\hline & 1.77 & & 956.932 & 0.77 & & 1.77 & & 921.061 & 0.74 & & 1.77 & & 915.253 & 0.73 \\
\hline & 1.47 & & 1190 & 0.79 & & 1.47 & & 1150 & 0.77 & & 1.47 & & 1150 & 0.77 \\
\hline & 1.18 & & 1520 & 0.81 & & 1.18 & & 1490 & 0.79 & & 1.18 & & 1490 & 0.79 \\
\hline \multirow{6}{*}{ L3 } & 3.54 & \multirow{6}{*}{0.06} & 337.592 & 0.54 & \multirow{6}{*}{ L6 } & 3.54 & \multirow{6}{*}{0.02} & 316.172 & 0.51 & \multirow{6}{*}{ L9 } & 3.54 & \multirow{6}{*}{0.08} & 302.123 & 0.48 \\
\hline & 2.95 & & 446.205 & 0.59 & & 2.95 & & 413.392 & 0.55 & & 2.95 & & 402.047 & 0.54 \\
\hline & 2.21 & & 693.922 & 0.69 & & 2.21 & & 657.723 & 0.66 & & 2.21 & & 645.561 & 0.65 \\
\hline & 1.77 & & 939.638 & 0.75 & & 1.77 & & 917.497 & 0.73 & & 1.77 & & 910.012 & 0.73 \\
\hline & 1.47 & & 1170 & 0.78 & & 1.47 & & 1150 & 0.77 & & 1.47 & & 1150 & 0.77 \\
\hline & 1.18 & & 1490 & 0.79 & & 1.18 & & 1490 & 0.79 & & 1.18 & & 1490 & 0.79 \\
\hline
\end{tabular}

Table 3 shows the results of models with longitudinal center opening and Fig. 9 shows the effect of opening area ratio on ultimate strength of models with both case 1 and case 2 with varying plate slenderness parameter. It is observed that the ultimate



Fig. 9 Effect of opening area ratio on ultimate strength of both transverse and longitudinal opening for varied plate slenderness parameter. 
Table 4 Results of models with longitudinal opening vs position ratio.

\begin{tabular}{|c|c|c|c|c|c|c|c|c|c|}
\hline \multirow[b]{2}{*}{ Model } & \multirow[b]{2}{*}{$\beta$} & \multicolumn{2}{|c|}{$\mathrm{PR}=0.2$} & \multicolumn{2}{|c|}{$\mathrm{PR}=0.4$} & \multicolumn{2}{|c|}{$\mathrm{PR}=0.6$} & \multicolumn{2}{|c|}{$\mathrm{PR}=0.8$} \\
\hline & & $\begin{array}{c}\text { Ultimate } \\
\operatorname{Load}\left(P_{u}\right) \\
K N\end{array}$ & $\frac{\sigma_{u}}{\sigma_{y}}$ & $\begin{array}{c}\text { Ultimate } \\
\text { Load }\left(P_{u}\right) \\
\quad K N\end{array}$ & $\frac{\sigma_{u}}{\sigma_{y}}$ & $\begin{array}{c}\text { Ultimate } \\
\operatorname{Load}\left(P_{u}\right) \\
\quad K N\end{array}$ & $\frac{\sigma_{u}}{\sigma_{y}}$ & $\begin{array}{c}\text { Ultimate } \\
\operatorname{Load}\left(P_{u}\right) \\
K N\end{array}$ & $\frac{\sigma_{u}}{\sigma_{y}}$ \\
\hline \multirow{4}{*}{ L1 } & 3.54 & 351.827 & 0.56 & 339.034 & 0.54 & 317.027 & 0.51 & 227.128 & 0.36 \\
\hline & 2.95 & 465.181 & 0.62 & 451.175 & 0.60 & 420.125 & 0.56 & 378.171 & 0.50 \\
\hline & 2.21 & 712.372 & 0.71 & 703.432 & 0.70 & 681.215 & 0.68 & 641.157 & 0.64 \\
\hline & 1.77 & 972.724 & 0.78 & 966.922 & 0.77 & 958.372 & 0.77 & 932.067 & 0.75 \\
\hline \multirow{4}{*}{ L2 } & 3.54 & 339.481 & 0.54 & 332.292 & 0.53 & 307.229 & 0.49 & 267.727 & 0.43 \\
\hline & 2.95 & 455.416 & 0.61 & 436.604 & 0.58 & 414.731 & 0.55 & 368.756 & 0.49 \\
\hline & 2.21 & 701.811 & 0.70 & 687.383 & 0.69 & 663.958 & 0.66 & 625 & 0.63 \\
\hline & 1.77 & 959.897 & 0.77 & 953.262 & 0.76 & 939.148 & 0.75 & 913.116 & 0.73 \\
\hline \multirow{4}{*}{ L3 } & 3.54 & 323.366 & 0.52 & 324.517 & 0.52 & 300.117 & 0.48 & 249.921 & 0.40 \\
\hline & 2.95 & 431.136 & 0.57 & 429.614 & 0.57 & 402.498 & 0.54 & 254.034 & 0.34 \\
\hline & 2.21 & 681.224 & 0.68 & 654.341 & 0.65 & 644.721 & 0.64 & 585.31 & 0.59 \\
\hline & 1.77 & 972.274 & 0.78 & 936.463 & 0.75 & 919.389 & 0.74 & 1010 & 0.81 \\
\hline \multirow{4}{*}{ L4 } & 3.54 & 326.867 & 0.52 & 316 & 0.51 & 284.002 & 0.45 & 244.855 & 0.39 \\
\hline & 2.95 & 430.22 & 0.57 & 419.38 & 0.56 & 392.95 & 0.52 & 345.974 & 0.46 \\
\hline & 2.21 & 670.347 & 0.67 & 650.37 & 0.65 & 627.974 & 0.63 & 585.212 & 0.59 \\
\hline & 1.77 & 923.821 & 0.74 & 916.814 & 0.73 & 897.395 & 0.72 & 868.448 & 0.69 \\
\hline \multirow{4}{*}{ L5 } & 3.54 & 318.717 & 0.51 & 309.792 & 0.50 & 286.369 & 0.46 & 242.759 & 0.39 \\
\hline & 2.95 & 421.352 & 0.56 & 409.383 & 0.55 & 383.037 & 0.51 & 334.019 & 0.45 \\
\hline & 2.21 & 659.435 & 0.66 & 636.026 & 0.64 & 609.537 & 0.61 & 566.577 & 0.57 \\
\hline & 1.77 & 908.401 & 0.73 & 891.437 & 0.71 & 874.49 & 0.70 & 842.619 & 0.67 \\
\hline \multirow{4}{*}{ L6 } & 3.54 & 309.233 & 0.49 & 301.463 & 0.48 & 278.348 & 0.45 & 236.771 & 0.38 \\
\hline & 2.95 & 415.179 & 0.55 & 401.519 & 0.54 & 372.191 & 0.50 & 327.047 & 0.44 \\
\hline & 2.21 & 651.991 & 0.65 & 613.295 & 0.61 & 590.652 & 0.59 & 550.869 & 0.55 \\
\hline & 1.77 & 898.656 & 0.72 & 870.545 & 0.70 & 850.532 & 0.68 & 817.744 & 0.65 \\
\hline \multirow{4}{*}{ L7 } & 3.54 & 302.541 & 0.48 & 300.188 & 0.48 & 262.351 & 0.42 & 223.637 & 0.36 \\
\hline & 2.95 & 408.957 & 0.55 & 398.043 & 0.53 & 358.104 & 0.48 & 317.482 & 0.42 \\
\hline & 2.21 & 648.298 & 0.65 & 611.191 & 0.61 & 574.576 & 0.57 & 538.034 & 0.54 \\
\hline & 1.77 & 895.203 & 0.72 & 854.807 & 0.68 & 824.159 & 0.66 & 796.819 & 0.64 \\
\hline \multirow{4}{*}{ L8 } & 3.54 & 301.214 & 0.48 & 294.97 & 0.47 & 262.384 & 0.42 & 222.195 & 0.36 \\
\hline & 2.95 & 403.589 & 0.54 & 387.269 & 0.52 & 354.238 & 0.47 & 306.646 & 0.41 \\
\hline & 2.21 & 644.88 & 0.64 & 606.561 & 0.61 & 559.725 & 0.56 & 519.235 & 0.52 \\
\hline & 1.77 & 891.621 & 0.71 & 846.721 & 0.68 & 782.792 & 0.63 & 778.943 & 0.62 \\
\hline \multirow{4}{*}{ L9 } & 3.54 & 296.712 & 0.47 & 293.522 & 0.47 & 193.597 & 0.31 & 165.824 & 0.27 \\
\hline & 2.95 & 399.381 & 0.53 & 390.942 & 0.52 & 289.75 & 0.39 & 210.897 & 0.28 \\
\hline & 2.21 & 639.935 & 0.64 & 603.664 & 0.60 & 445.124 & 0.45 & 388.639 & 0.39 \\
\hline & 1.77 & 886.892 & 0.71 & 841.265 & 0.67 & 664.767 & 0.53 & 580.388 & 0.46 \\
\hline
\end{tabular}


strength of models with longitudinal opening changes a little with varying $A R$. Meanwhile, for models with transverse opening, the ultimate strength changes a lot for different $A R$. Also, it can be also found that when plate slenderness parameter is less than 1.77, the variation of ultimate strength of plate with transverse opening is linear while the variation is nonlinear for plate slenderness parameter greater than 1.77 .

Regarding opening area ratio of 0.04 , the effect of position ratio on ultimate strength of plate with both transverse and longitudinal opening for varying plate slenderness parameter is shown in Fig. 10. As it can be seen in Fig. 10, the ultimate strength varies a little with respect to PR in case of models with transverse opening. Meanwhile, the change is very great for models with longitudinal opening. For $\beta=3.54,2.95,2.21,1.77$ and 1.47 , the corresponding variance ratio of case 2 is 23.04 , $19.93,11.21,4.58$ and $0.84 \%$ respectively. Furthermore, the influence of opening position ratio on the ultimate strength of models with longitudinal opening must be taken into account when plate slenderness parameter is greater than 1.77. The results of other models with plate slenderness parameter of greater than 1.77 are shown in Table 4.

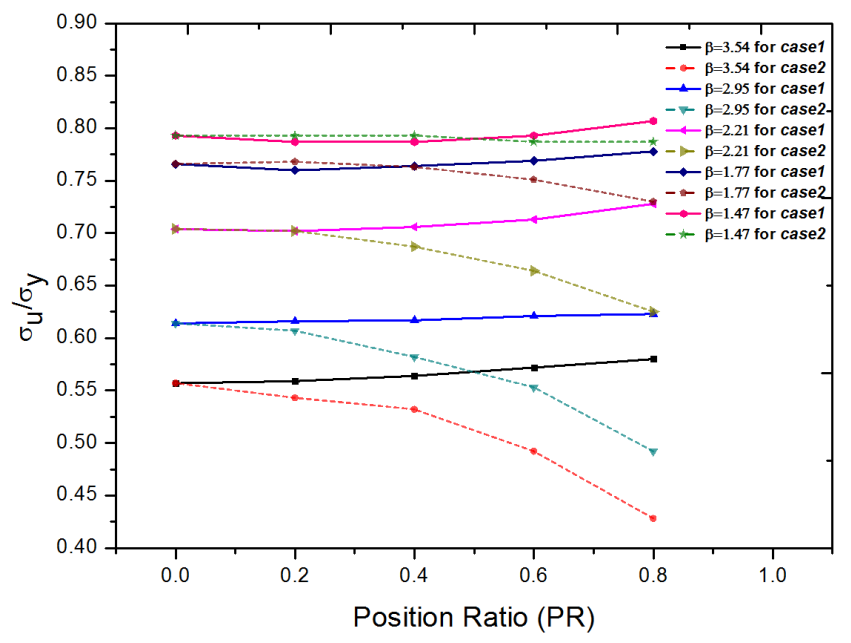

Fig. 10 Effect of position ratio on ultimate strength for models with $A R$ of 0.04 .

\section{DESIGN FORMLAE FITTING}

Empirical formulae are useful in practical design. In the present study, the formulae to predict the strength reduced parameter $\left(\frac{\sigma_{u}}{\sigma_{y}}\right)$ of plate with rectangular opening are categorized into three types:

- Type 1 : ultimate strength for plates of slenderness parameter 1.18 3.54 with transverse opening.

- Type 2 : ultimate strength for plates of slenderness parameter 1.18 3.54 with longitudinal center opening $(P R=0)$ and plates of slenderness parameter1.77 3.54 with longitudinal side opening $(P R \neq 0)$.

- Type 3 : ultimate strength for plates of slenderness parameter $1.18 \sim 1.77$ with longitudinal side opening $(P R \neq 0)$.

The effect of yield stress $\left(\sigma_{y}\right)$ and modulus of elasticity $(E)$ of the plate can be taken into account in the calculation of plate slenderness parameter $(\beta)$, consequently, for the first and second types, the equation to predict the strength reduced para$\operatorname{meter}\left(\frac{\sigma_{u}}{\sigma_{y}}\right)$ can be the function of plate slenderness parameter $(\beta)$ and plate opening area ratio $(A R)$. For the third type, the equation to predict the strength reduced parameter $\left(\frac{\sigma_{u}}{\sigma_{y}}\right)$ should be, however, the function of plate slenderness parameter $(\beta)$, plate opening area ratio $(A R)$ and opening position ratio $(P R)$. The general form of strength reduction parameter can be expressed as following:

$$
y=b_{0}+b_{1} f_{1}\left(x_{j}\right)+b_{2} f_{2}\left(x_{j}\right)+\cdots+b_{p} f_{p}\left(x_{j}\right)
$$


Where, $b_{i}$ are unknown coefficients to be determined through regression analysis. $x_{j}$ are independent variables, that is, $\beta$, $A R$ and $P R$. Functions $f_{1}, f_{2}, \cdots, f_{p}$ are assumed to be:

$$
f_{k}\left(x_{j}\right)=x_{1}^{d_{k, 1}} x_{2}^{d_{k, 2}} \cdots x_{n}^{d_{k, n}}
$$

Regarding the predicting formula for type1 and type2, the influence of $P R$ can be ignored, and therefore Eq. (2) can be expressed in the simpler form as following:

$$
f_{k}(\beta, A R)=\beta^{d_{k, 1}}(A R)^{d_{k, 1}}
$$

Since the fitted formulae have only two variables, "sftool" command of MATLAB is expedient for fitting the surfaces. The type of fitted equation is selected as polynomial. Furthermore, ensuring mean of ratios of $\left(\frac{\sigma_{u}}{\sigma_{y}}\right)_{\text {pre }}$ to $\left(\frac{\sigma_{u}}{\sigma_{y}}\right)_{\text {num }}$ (as defined below) is around 1.0 as well as $C O V$ of less than $10 \%$, the polynomial is fitted with least order as possible.

However, $P R$ must be considered for type3 predicting formula, method of surface fitting is invalid. To solve this problem, only second item in Eq. (1) is taken into account,

$$
\frac{\sigma_{u}}{\sigma_{y}}=b_{1} \beta^{d_{1,1}}(A R)^{d_{1,2}}(P R)^{d_{1,3}}
$$

Taking the natural logarithm for both sides of above expression yields,

$$
\ln \left(\frac{\sigma_{u}}{\sigma_{y}}\right)=\ln b_{1}+d_{1,1} \ln \beta+d_{1,2} \ln (A R)+d_{1,3} \ln (P R)
$$

\begin{tabular}{|c|c|c|}
\hline & Center Opening $(P R=0)$ & Side Opening $(P R \neq 0)$ \\
\hline $\begin{array}{l}\text { Transverse } \\
\text { opening }\end{array}$ & $\begin{aligned} \frac{\sigma_{u}}{\sigma_{y}} & =1.2-0.19 \beta-6.09(A R)+2.17 \beta(A R) \\
& -4.98(A R)^{2}-6.15 \beta(A R)^{2}+25.25(A R)^{3}\end{aligned}$ & Same as centrally Opening \\
\hline & & Same as centrally opening, $\beta<1.77$ \\
\hline $\begin{array}{l}\text { Longitudinal } \\
\text { opening }\end{array}$ & $\begin{aligned} \frac{\sigma_{u}}{\sigma_{y}} & =0.96-0.1 \beta-0.36(A R) \\
& +0.27 \beta(A R)+2.13(A R)^{2}\end{aligned}$ & $\begin{array}{l}\frac{\sigma_{u}}{\sigma_{y}}=0.68 \beta^{-0.64}(A R)^{-0.1}(P R)^{-0.156} \\
, \quad \beta<1.77\end{array}$ \\
\hline
\end{tabular}

Using the results in Tables 2, 3 and 4, coefficients $b_{1}, d_{1,1}, d_{1,2}$, and $d_{1,3}$ can be determined by the least square method. The final design equations are shown in Table 5.

Table 5 Design formulae fitted by simulation results.

Defined is $\left(\frac{\sigma_{u}}{\sigma_{y}}\right)_{\text {pre }}$ as the value obtained by above formulae and $\left(\frac{\sigma_{u}}{\sigma_{y}}\right)_{n u m}$ as the value obtained by numerical calculation. Comparison between them is shown in Figs. 11 to 13. In Fig. 11 and 12, the dots indicate the numerical value meanwhile 
the surfaces represent Eqs. (6) and (7). Means of the ratios of $\left(\frac{\sigma_{u}}{\sigma_{y}}\right)_{\text {pre }}$ to $\left(\frac{\sigma_{u}}{\sigma_{y}}\right)_{\text {num }}$ are $0.983,1.012$ and 0.984 for Eqs. (6), (7) and (8), respectively, and their $C O V$ s are 2.84, 1.72 and 9.9\% for Eqs. (6), (7) and (8), respectively. The mean and $C O V \mathrm{~s}$ of design formulae are quite good. Therefore it can be said that they can be practically used in design of plate members.



Fig. 11 Comparison of Eq. (6) with numerical results.



Fig. 12 Comparison of Eq. (7) with numerical results.



Fig. 13 Comparison of Eq. (8) with numerical results. 


\section{SUMMARY AND CONCLUSIONS}

This study has been mainly concerned with the ultimate strength of plate having two different types opening (case 1 and case 2) under uniaxial compression. Furthermore, the effect of opening position on ultimate strength has been investigated. Based on the present numerical results, the design formulae considering all influence factors are proposed.

Variation of ultimate strength with different slenderness parameter $(\beta)$ and opening area ratio $(A R)$ for the plate with transverse opening (case1) is much higher than the plate with longitudinal opening (case2). For slenderness parameter of 1.18 3.54 and area ratio more than 0.12 , the models with transverse center rectangular opening fail by yielding. Moreover, as plate slenderness parameter is less than 1.47 , the plate also fails by yielding regardless of opening area ratio. In addition to these findings, when plate slenderness parameter is less than 1.77, the variation of ultimate strength of plate with transverse opening is linear meanwhile the variation is nonlinear for plate slenderness parameter more than 1.77.Opening position ratio ( $P R$ ) has no effect on the ultimate strength of plate with transverse opening. However, the influence of opening position ratio on the ultimate strength of plate with longitudinal opening depends on the plate slenderness parameter $(\beta)$ : when $\beta$ is less than 1.77, the influence can be neglected, and otherwise the influence must be considered. From the comparison of predicting formulae with numerical results, the equations proposed in this study can be used in real practice.

\section{ACKNOWLEDGEMENTS}

This research was supported by World Class University (WCU) program through the Korea Science and Engineering Foundation (R33-10150), by Mid-career Researcher Program NRF grant (2011-0027557) funded by the Ministry of Education, Science and Technology and by Basic Science Research Program through the National Research Foundation of Korea (NRF) funded by the Ministry of Education, Science and Technology (2011-0003030).

\section{REFERENCE}

Bambach, M.R. BE and Rasmussen, K.J.R. MScEng., 2002. Tests of unstiffened elements under combined compression and bending. Research Report No R818 of the University of Sydney.

Cui, W.C. and Mansour, A.E., 1998. Effects of welding distortions and residual stresses on the ultimate strength of long rectangular plates under uniaxial compression. Marine Structures, 11, pp.251-269.

Jwalamalini, R., Sundaravadivelu, R., Vendhan, C.P. and Ganapathy, C., 1992. Stability of initially stressed square plates with square openings. Marine Structures, 5(1), pp.71-84.

Khaled, M. El-S., Aly, S.N. and Mohammad, I., 2004. Elasto-plastic buckling of perforated plates under uniaxial compression. Thin-Walled Structures, 42(8), pp.1083-1101.

Kumar, M. Suneel., Alagusundaramoorthy, P. and Sundaravadivelu, R., 2007. Ultimate strength of square plate with rectangular opening under axial compression. Journal of Naval Architecture and Marine Engineering, 4(1), pp.15-26.

Madasamy, C.M. and Kalyanaraman, V., 1994. Ayalysis of plated structures with rectangular cutouts and internal supports using the spline finite strip method. Computers and Structures, 52(2), pp.277-286.

Mohtaram, Y.F., Kahnamouei, J.T., Shariati, M. and Behjat, B., 2011. Experimental and numerical investigation of buckling in rectangular steel plates with groove-shape cut out. Journal of Zhejiang University SCIENCE A, 13(6), pp.469480.

Motok, M.D., 1997. Stress concentration on the contour of a plate opening an arbitrary corner radius of curvature. Marine Structures, 10(1), pp.1-12.

Narayanan, R. and Chow, F.Y., 1984. Ultimate capacity of uniaxial compressed perforated plates. Thin-Walled Structures, 2(3), pp.241-264.

Narayanan, R. and Chan, S.L., 1985. Ultimate capacity of plates containing holes under linearly varying edge displacements. Computers and Structures, 21(4), pp.841-849.

Paik, J.K., Thayamballi, A.K. and Kim, D.H., 1999. An analytical method for the ultimate compressive strength and effecttive plating of stiffened panels. Journal of Constructional Steel Research, 49(1), pp.43-68. 
Paik, J.K., Thayamballi, A.K. and Kim, B.J., 2001. Advanced ultimate strength formulations for ship plating under combined biaxial compression/tension, edge shear, and lateral pressure loads. Marine Technology, 38(1), pp.153-164.

Roberts, T.M. and Azizian, Z.G., 1984. Strength of perforated plates subjected to in-plane loading. Thin-Walled Structures, 2(2), pp.153-164.

Shanmugam, N.E., Thevendran, V. and Tan, Y.H., 1999. Design formula for axially compressed perforated plates. ThinWalled Structures, 34(1), pp.1-20.

Toulios, M. and Caridis, P.A., 2002. The effect of aspect ratio on the elasto-plastic response of stiffened plates loaded in uniaxial edge compression. Computers and Structures, 80(14-15), pp.1317-1328. 